\title{
CULTURAS ESCOLARES: O ESTADO DA ARTE NA ÁREA EDUCACIONAL
}

\author{
Leila Adriana BAPTAGLIN ${ }^{1}$ \\ Gislaine Aparecida Rodrigues da Silva ROSSETTO ${ }^{2}$
}

RESUMO: Este estudo objetiva realizar um estado da arte referente à utilização do termo cultura escolar nas teses de doutorado encontradas no portal da CAPES. Esse objetivo surgiu com a problemática de verificar a origem do termo culturas escolares, como ele foi inserido e como se apresenta nas pesquisas vinculadas ao campo Educacional. Desta forma foi realizado um levantamento dos resumos das teses de doutorado, referentes ao período de 1987 a 2009, arquivados no Portal da CAPES. A análise dos resumos das teses foi realizada em três etapas: 1- pré-análise; 2- exploração e; 3- tratamento dos resultados. Na categorização das 51 teses temos dois blocos: (1)Cultura e as implicações no contexto escolar, o qual se subdivide em: a) História Cultural (mudanças nas culturas escolares) e; b) Cultura versus Culturas Escolares e; (2)- Cultura Escolar e sua relação com o trabalho docente, que se subdivide em: a) Culturas escolares (docentes e discentes - organização do tempo e espaço escolar), b) Cultura versus Políticas Públicas, c) Cultura versus Currículo e, d) Cultura escolar versus Educação Especial. Percebemos assim, que os estudos que discutem a cultura escolar nos sinalizam para a complexidade da mesma, bem como do trabalho escolar e do trabalho docente.

PALAVRAS-CHAVE: Culturas escolares. Trabalho escolar. Trabalho docente.

\section{Introdução}

Cultura é um termo recorrentemente utilizado nos discursos e nas pesquisas acadêmico-científicas de diferentes áreas do conhecimento, o que de fato diversifica a

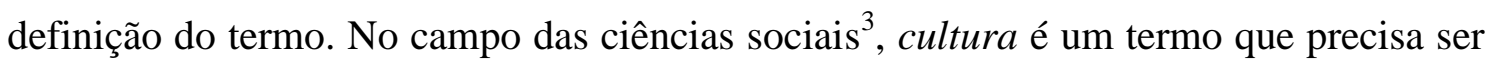
definido para que, mesmo comprimido, possa representar as mudanças que foram sendo realizadas ao longo dos tempos (GEERTZ, 1989). Compreender a construção do conceito de cultura e a forma como este vem sendo apropriado pela área educacional

\footnotetext{
${ }^{1}$ Doutora em Educação. UFSM - Universidade Federal de Santa Maria. Professora do Curso de Artes Visuais (Licenciatura). UFRR - Universidade Federal de Roraima. Boa Vista - RR - Brasil. 69310-000 leila.baptaglin@ufrr.br.

2 Doutora em Educação pelo Programa de Pós-graduação em Educação (PPGE) e Professora. UFSM Universidade Federal de Santa Maria. Santa Maria - RS - Brasil. 97105-900 gislainesilvarossetto@gmail.com.

${ }^{3}$ O campo das ciências sociais envolve as áreas da Antropologia, da Filosofia, da História, da Linguística, da Educação (envolvendo a pedagogia, a psicologia da educação, a sociologia da educação, a filosofia da educação e a didática, dentre outras).
} 
nas pesquisas acadêmico-científicas, torna-se algo estritamente necessário para que possamos, como coloca Geertz (1989), definir o conceito que utilizaremos em nossas pesquisas relativas à cultura escolar.

Apresentaremos, neste texto, um estudo a partir do qual buscamos trazer a origem do termo cultura nas diferentes formas como ele foi e ainda é utilizado na área educacional. Para isso, realizaremos um estudo do estado da arte das produções acadêmico-científicas, mais especificamente, teses de doutorado, arquivados no Portal da Coordenação de Aperfeiçoamento de Pessoal de Nível Superior, a CAPES.

Os estudos do estado da arte, também chamados de o estado do conhecimento, permitem conhecer o que se tem produzido na área acerca do tema em foco, sinalizando orientações que as investigações têm tomado. Essa compreensão nos possibilitou contribuir na análise do tema dentro de um campo, de uma aérea de pesquisa (ROMANOWSKI; ENS, 2006). Desse modo, entendemos que o estudo do estado da arte seja uma etapa imprescindível para o desenvolvimento de qualquer produção de pesquisa que se diga acadêmico-científica. Entretanto, este processo apresentou-se de forma complexa, uma vez que tivemos uma grande quantidade de trabalhos produzidos e à disposição para consulta do público interessado mediante variados meios de divulgação da produção de trabalhos de pesquisa.

Consideramos que o estudo do estado do conhecimento ou estado da arte, é uma forma de investigação teórica, além de constituir-se em um mapeamento inicial acerca um determinado tema em estudo, sem que haja uma preocupação, pelo menos imediata, com a construção de uma teoria ou com uma intervenção teórica sobre um campo do conhecimento. $\mathrm{O}$ estudo do estado da arte pode ser definido como o momento em que se selecionam as fontes de busca e/ou banco de dados, os descritores ao mesmo tempo em que se sistematizam os mesmos de modo que os tornem de fácil acesso em uma próxima etapa, ou seja, na ocasião da descrição e análise dos materiais reunidos (CORTE; MOROSINI, 2007). É nessa perspectiva que o estado da arte do termo cultura escolar surge, pois, no intuito de traçarmos um panorama geral do que se tem trabalhado sobre o termo cultura na área educacional, a primeira denominação emerge como um termo representativo que agrega os dois conceitos (cultura e escola).

O estudo do estado da arte sobre cultura escolar se deu em fontes representativas das publicações acadêmico-científicas a partir do banco de dados de teses da CAPES. Este levantamento foi realizado em pesquisas de doutoramento concluídas no período de 1987 a 2009. Como dissemos, utilizamos, para o 
levantamento, a expressão cultura escolar e não somente o termo cultura. Esse procedimento se deu a fim de direcionar para as pesquisas que trabalham com o termo cultura na educação haja vista, a grande diversidade de pesquisas que utilizam este termo em outros campos do conhecimento.

Para compreender como o campo educacional se apropria do conceito de cultura, procuramos, com a leitura dos resumos das teses de doutorado, realizar um esforço de agrupar estes títulos em categorias a fim de verificarmos como esse campo vem se apropriando desse conceito. A elaboração das categorias se deu a partir de uma análise de conteúdo. Este tipo de análise tem a finalidade de verificar nos textos, algumas características particulares ou categorias conceituais que permitam passar dos elementos descritivos a uma investigação mais aprofundada destas mesmas características que perfazem o contexto em que são produzidas as informações. Segundo Szymansky (2004), as etapas no processo da análise de conteúdo são: pré-análise descrição analítica ou exploração do material, tratamento dos resultados obtidos e interpretação inferencial.

A relevância deste estudo se dá pela necessidade de apresentarmos, neste momento, uma definição, mesmo que embrionária e flexível, de como estaremos nos apropriando do conceito de cultura em nossas pesquisas relativas à cultura escolar. E, para verificar como o conceito de cultura, mais especificamente na cultura escolar, tem sido apropriado no campo educacional, procuraremos responder algumas questões como: Quais foram os autores mais citados nas teses de doutoramento no Brasil? Onde se concentram (Estados brasileiros) os estudos relativos à cultura escolar? Estes são os questionamentos que procuraremos responder e, com as respostas destes esperamos encontrar direcionamentos que nos possibilitem compreender como o campo educacional se apropria do conceito de cultura.

\section{Cultura no campo educacional: a construção do caminho investigativo e primeiros apontamentos para um Estado da Arte}

As reflexões sobre cultura no campo educacional, no Brasil, tomaram corpo na segunda metade do século XX intensificando-se na esfera teórica, nos últimos trinta anos, a partir das discussões em torno da crise dos sistemas educacionais impulsionadas por Bourdieu e Passeron (1975). Esta crise colocou, e tem colocado, o desafio de refletir sobre as reformas educacionais e a busca de novos referenciais teóricos para interpretar 
o universo escolar. Isso pôde ser evidenciado no levantamento que realizamos nas pesquisas acadêmico-científicas no contexto educacional, em nível de doutoramento, nas quais, a expressão cultura escolar começa a ser utilizada com ênfase somente na década de 90.

Essas constatações foram possíveis de serem observadas por meio do levantamento realizado no banco de teses da CAPES onde, no período de 1987 a 2009, foi levantado, com base na expressão cultura escolar, um total de 124 títulos de teses. Contudo, em uma primeira análise, dos 124 títulos, apenas 51 apresentaram em seu título ou em suas palavras-chave a expressão cultura escolar. Porém, percebemos que no período de 1987 a 1995 não houve nenhuma pesquisa de doutorado contendo a referida expressão, isso ocorre somente a partir de 1996.

Entre 1996 a 2000 temos a produção de 6 teses. No Entanto, é na primeira década do século XXI que temos a intensificação dos estudos relativos a esta temática. Nos anos de 2000 a 2009 estão registrados 45 teses que contém em seu título ou em suas palavras-chaves, a expressão cultura escolar.

Além das constatações citadas, foi possível realizar, a partir da leitura dos resumos dessas mesmas 51 pesquisas de doutorado, um levantamento no qual observamos alguns dos teóricos mais utilizados ao tratar do conceito de cultura e cultura escolar, sendo eles vinculados a algumas correntes metodológicas. Na História cultural temos Marc Bloch, Michel de Certeau, Jacques Le Goff; Clifford Geertz e Roger Chartier. Na Teoria da cultura temos Raymond Williams. E, na cultura escolar temos Antônio Viñao Frago, Dominique Julia e Luciano de Mendes Faria Filho.

Percebemos, então, que quanto ao termo cultura temos cinco autores que tratam esse conceito na perspectiva da história e um autor que aborda o termo na perspectiva de uma teoria, ou seja, de uma construção teórica/cultural. Neste estudo, buscamos dar ênfase à expressão cultura escolar, ou seja, aos autores Antônio Viñao Frago, Dominique Julia e Luciano de Mendes Faria Filho.

Dominique Julia foi professor do Instituto Universitário Europeu (Florença/Itália) e no Brasil, o texto "A cultura escolar como objeto histórico" (JULIA, 2001) publicado na Revista Brasileira de História da Educação tem sido insistentemente citado nas pesquisas relativas à escola com o intuito de conceituar a cultura escolar. Para este autor, 
que definem conhecimentos a ensinar e condutas a inculcar, e um conjunto de práticas que permitem a transmissão desses conhecimentos e a incorporação desses comportamentos; normas e práticas coordenadas a finalidade que podem variar segundo as épocas (finalidade religiosa, sociopolítica ou simplesmente de socialização).(JULIA, 2001, p.10)

Julia (2001) é a base para as produções brasileiras voltadas para a cultura escolar. Antônio Viñao Frago é professor da Universidade de Murcia (Espanha) e apresenta poucas produções que chegaram ao Brasil sendo elas, o artigo "Historia de la educación e historia cultura" (VIÑAO FRAGO, 1995) publicado na Revista Brasileira de Educação e na conferência de abertura do I Congresso Brasileiro de História da Educação (Culturas escolares) proferida em 2000 e publicada em 2001, pela Sociedade Brasileira de História da Educação. Para Viñao Frago (1995, p.69),

Y sí, es cierto, la cultura escolar es toda la vida escolar: hechos e ideas, mentes y cuerpos, objetos y conductas, modos de pensar, decir $y$ hacer. Lo que sucede es que en este conjunto hay algunos aspectos que son más relevantes que otros, en el sentido que son elementos organizadores que la conforman y definen. Dentre ellos elijo dos a lo que he dedicado alguna atención en los últimos años: el espacio y el tiempo escolares. Otros no menos importantes, como las prácticas discursivas y linguísticas o las tecnologías y modos de comunicación empleados, son ahora dejados a un lado ${ }^{4}$.

Luciano Mendes de Faria Filho é professor da Universidade Federal de Minas Gerais (UFMG) e trabalha com o campo educacional e da história da educação. Para este autor, a noção de escolarização

[...] remete a dois sentidos que se relacionam: o estabelecimento de processos e políticas de "organização" de uma rede de ensino e a paulatina produção de referências sociais que a escola se torna eixo articulador de sentidos e significados. (FARIA FILHO et al., 2004, p.153).

Faria filho et al. (2004), no artigo publicado na revista Educação e Pesquisa, intitulado "A cultura escolar como categoria de análise e como campo de investigação na história da educação brasileira" traz uma síntese das investigações que vêm sendo

${ }^{4}$ E se, em certo, a cultura escolar é toda a vida escolar: atos e ideias, mentes e corpos, objetos e condutas, modos de pensar, dizer e fazer. O que sucede é que neste conjunto há alguns aspectos que são mais relevantes que outros, no sentido que são elementos organizadores que a conformam e definem. Dentre eles elejo dois os quais se há dedicado alguma atenção nos últimos anos: o espaço e o tempo escolares. Outros menos importantes, como as práticas discursivas e linguísticas ou as tecnologias e modos de comunicação empregados, são agora deixados de lado. (VIÑAO FRAGO, 1995, p.69, tradução nossa). 
realizadas pelos pesquisadores e a forma como a cultura escolar vem sendo apropriada pela área da história da educação brasileira como categoria de análise e campo de investigação. Neste artigo, Faria Filho et al. (2004) apresenta as definições de cultura escolar mais utilizadas nos trabalhos de Dominique Júlia, Antônio Viñao Frago, André Chervel, Jean-Claude Forquin.

Além dos autores verificados em nosso levantamento, percebemos que Faria Filho et al. (2004) apresenta outros dois autores que são base para a construção do conceito de cultura escolar, são eles: André Chervel e Jean-Claude Forquin.

Assim, com base na pré-análise realizada nos resumos das 51 teses de doutoramento, evidenciamos o que chamaremos de duas categorias que se subdividem em dimensões categorias (Quadro 1). As dimensões categorias configuram-se no que podemos chamar de estruturas macro representativas dos agrupamentos que foram sendo realizados a partir das temáticas presentes nas teses. Apresentam-se assim, como estruturas que abarcam o conteúdo central das teses. Consequentemente, delineadas as dimensões categoriais, temos com maior clareza as categorias de análise do estudo. A categoria de análise é o elemento que representa de forma sintética o que se pode perceber nos temas das teses tendo em vista o objetivo do estudo.

Com base nesta estruturação, temos a categoria Cultura e as implicações no contexto escolar e Cultura Escolar e sua relação com o trabalho docente. A primeira categoria apresenta algumas dimensões categoriais as quais se configuram em: História Cultural (mudanças nas culturas escolares) e, Cultura versus Culturas escolares. A segunda categoria apresenta as dimensões: Culturas escolares (docentes e discentes organização do tempo e espaço escolar); Cultura versus Políticas Públicas; Cultura versus Currículo; e, por fim, Cultura escolar versus Educação Especial.

Quadro 1 - Pré-análise dos resumos das 51 teses de doutoramento

\begin{tabular}{|c|c|c|}
\hline Categorias & Dimensões categoriais & $\mathbf{N}^{\mathbf{o}}$ de títulos \\
\hline \multirow{2}{*}{$\begin{array}{c}\text { Cultura e as implicações no } \\
\text { contexto escolar }\end{array}$} & $\begin{array}{l}\text { História Cultural (mudanças } \\
\text { nas culturas escolares) }\end{array}$ & 20 títulos \\
\hline & $\begin{array}{c}\text { Cultura versus Culturas } \\
\text { escolares }\end{array}$ & 10 títulos \\
\hline $\begin{array}{l}\text { Cultura escolar e sua } \\
\text { relação com o trabalho } \\
\text { docente }\end{array}$ & $\begin{array}{l}\text { Culturas Escolares (docentes e } \\
\text { discentes - organização do } \\
\text { tempo e espaço escolar) }\end{array}$ & 10 títulos \\
\hline
\end{tabular}




\begin{tabular}{||c|c||c||}
\hline \hline & $\begin{array}{c}\text { Cultura versus Políticas } \\
\text { Públicas }\end{array}$ & 4 títulos \\
\cline { 2 - 3 } & Cultura versus Currículo & 3 títulos \\
\cline { 2 - 3 } & $\begin{array}{c}\text { Cultura Escolar versus } \\
\text { Educação Especial }\end{array}$ & 4 títulos \\
\hline
\end{tabular}

Fonte: Elaboração própria.

$\mathrm{Na}$ primeira categoria, Cultura e as implicações no contexto escolar,

observamos que há evidências de que ocorrem mudanças realizadas no contexto escolar, mesmo sendo mínimas. E são a partir dessas mudanças que os trabalhos apresentados na categoria História cultural (mudanças nas culturas escolares) se configuram. Dos 51 títulos de teses de doutorado analisados, 20 apresentam-se nesta categoria, o que sinaliza para a ênfase dos estudos das culturas escolares no campo histórico das modificações/transformações sociais.

Ortiz (2006), ao tratar da cultura no contexto mundial, coloca que, cada civilização, presente ou passada construiu um universo singular. Citando os Estudos sobre História de Toynbee (1971), Ortiz (2006) coloca a civilização e a cultura com um ciclo de vida que vai do nascimento, crescimento e a morte. Assim, “[...] todo este esforço consiste em apreender a gênese e o declínio das formações sociais, na esperança de descobrir uma lógica na sequência de surgimentos e desaparecimentos das culturas humanas". (ORTIZ, 2006, p.71).

Essas considerações feitas por Ortiz enfatizam a necessidade de verificarmos o desenrolar das diferentes culturas nas diferentes civilizações posto que elas repercutem diretamente nas instituições, na sociedade e, a Escola certamente é uma delas. Dessa forma, cada civilização, cada cultura tem um processo de nascimento, crescimento e morte e, na Escola isso não é diferente. Assim, os títulos vinculados à dimensão categorial História Cultural (mudanças nas culturas escolares) procuram trazer um histórico das modificações feitas na estrutura, na organização e na filosofia das Instituições Educacionais.

Ao referirmos a diferentes Instituições Educacionais, podemos sinalizar que estas diferenças se dão, como colocado por Laraia (1999), não apenas pelo determinante biológico, geográfico, ou histórico, mas, sim, pelo conjunto destas características. Com isso, a dimensão categorial Cultura versus Culturas escolares sinaliza para a repercussão deste conjunto de características peculiares a cada civilização, no contexto 
escolar. Nesse sentido, as culturas escolares, por mais que estejam integradas num contexto social e cultural mais amplo, produzem culturas que lhes são próprias e que exprimem os valores e as crenças que os membros pertencentes a essa organização partilham por meio do trabalho realizado pelos sujeitos pertencentes ao espaço escolar (NÓVOA, 2005). Assim, a cultura escolar nos remete:

[...] para a existência, em cada escola, de um conjunto de factores organizacionais e processos sociais específicos que relativizam a cultura escolar (enquanto expressão dos valores, hábitos, comportamentos, transmitidos pela forma escolar de educação a partir de determinações exteriores) e que, por isso, demonstram que não se trata de um receptáculo passivo de instruções exteriores, mas um elemento activo na sua reinterpretação e operacionalização. (CARVALHO, 2006, p.6)

Com isso, podemos perceber que a cultura escolar não é algo que se impõe ao espaço da Escola, mas algo que se constrói paulatinamente e se desenvolve na interação social dos membros que compõem este contexto educacional. Cada sujeito que pertença a uma determinada cultura(s) escolar(es) é produtor e reprodutor de sentidos concretos delineados pelas normativas legais, pelo local de trabalho e pelos objetivos institucionais, mesmo que inconscientemente. Considerando-se que suas ações são o produto de um modo de agir que se concretiza, mesmo o sujeito não sendo o produtor imediato e nem tendo domínio e/ou consciência de sua repercussão.

Com isso, percebemos que a representatividade de um grupo "[...] obedece a modelos culturais interiorizados, ainda que as expressões pessoais apresentem sempre variações em conflito com as tradições.” (MINAYO, 2006, p.208). É nesse limiar, que a consciência individual se expressa na consciência coletiva e vice-versa. E, é nesta cultura colaborativa que se concretiza a cultura escolar da instituição escola. Esta, em condições adversas, sob outras condições de vida social pode ser diferente, ratificando a proposição de que pequenas mudanças proporcionam a tessitura de tramas distintas no processo de constituição de uma cultura escolar.

Neste contexto, percebemos que os docentes são os elementos centrais desta cultura escolar. Isso posto, as crenças e concepções teóricas implícitas, que os mesmos apresentam em relação a seu trabalho pedagógico, podem sinalizar as formas como processam e transpõem as informações e os conhecimentos. Constroem assim, seus conhecimentos pedagógicos que podes ou não se configurarem em um conhecimento compartilhado entre os pares na instituição educacional. 
E é na interlocução desta discussão que temos a categoria Culturas escolares $\boldsymbol{e}$ sua relação com o trabalho docente, a qual apresenta dimensões categoriais que sinalizam para a existência de ramificações mais específicas que nos permitem falar da cultura escolar e a relação como trabalho docente. Os trabalhos vinculados à dimensão categorial Culturas escolares (docentes e discentes - organização do tempo e espaço escolar) referem-se à forma como a cultura é apropriada pelo contexto escolar e como esta passa a ser redimensionada neste espaço. Embora tenhamos uma organização escolar previamente posta, uma "Cultura Ideal” de escola (OLIVEIRA, 2003), a cultura histórico-social, mesmo que de forma tênue, influencia na reorganização destes espaços. Pérez Gómez (apud OLIVEIRA, 2003, p.151) situa esta influência quando diz que as demandas externas à escola:

[...] derivam em meros simulacros formais que nada mudam a realidade dos intercâmbios da aula, embora modifiquem a linguagem e o jargão profissional. Desta maneira, as reformas apenas formais provocam a saturação de atividades burocráticas dos docentes sem modificar a qualidade da prática.

Com base nesta colocação de Pérez Gómez (apud OLIVEIRA, 2003) e nas sinalizações feitas pelos demais autores, percebemos uma similaridade entre culturas escolares e trabalho escolar. No entanto, apesar desta similaridade, temos uma clara distinção entre estes dois conceitos. Embora com uma "delimitação" bastante tênue, o que percebemos é que a cultura escolar está em um plano de maior abrangência que o trabalho escolar, ou seja, as culturas escolares são amplas e possibilitam a inserção de uma rede de escolas em uma mesma cultura escolar. O trabalho escolar, embora possa se apropriar da cultura escolar, ele apresenta especificidades conforme a realidade da escola configurada pelos docentes, pelos alunos, pelos servidores e pelas próprias peculiaridades da comunidade (TARDIF; LESSARD, 2005).

E nesta construção da cultura escolar, os docentes são os elementos centrais. Desse modo, as crenças e concepções teóricas implícitas que os mesmos apresentam também em relação a seu trabalho pedagógico podem sinalizar as formas como processam e transpõem as informações e os conhecimentos para esse âmbito de seu trabalho. Constroem, assim, seu conhecimento pedagógico que pode ou não se configurar em um conhecimento compartilhado entre os pares na instituição.

A dimensão categorial Cultura versus Políticas Públicas tem uma forte relação com as culturas escolares e como trabalho escolar posto que explícita de forma clara 
como as prescrições externas são acolhidas nestes espaços. Para Viñao Frago (apud OLIVEIRA, 2003, p.150),

O caráter fundamentalmente histórico da cultura da escola e o histórico de reforma que ignora a sua existência, explicaria a superficialidade das reformas educativa, entendendo que "estas, em geral, se limitam a roçar a epiderme da atividade educativa sem modificar a escolar real, a realidade cotidiana de dita atividade e a vida dos estabelecimentos escolares.

Esta consideração feita por Viñao Frago (2001) delibera acerca da inadequada forma pela qual as Políticas Públicas são inseridas nas escolas. Elas são inseridas na cultura escolar e no trabalho escolar, porém não mobilizam estes espaços para a concretização do trabalho docente. As Políticas Públicas apenas circunscrevem um perímetro macro sem adentrarem nas micros ações que acontecem no desenvolvimento do trabalho docente.

Sabemos que esta é uma consideração bastante prudente posto que, na dimensão categorial Cultura versus Currículo, as pesquisas de doutoramento mostram que os conteúdos curriculares prescritos externamente à escola pouco são modificados para atender a cultura escolar. Isso pode ser evidenciado, na forma de um exemplo, quando tratamos da dimensão categorial Cultura versus Educação Especial, onde as pesquisas vinculadas a esta categorização colocam as dificuldades para a implementação de Políticas Públicas e ações que possibilitem aos Portadores de Necessidades Educacionais Especiais, o acesso e a permanência na educação escolar.

A partir desta explanação sobre os o conceito de cultura escolar referendados no campo teórico das teses de doutorado do banco de teses da CAPES, podemos perceber que este conceito vincula-se fortemente à área da história da educação posto que, para seu entendimento, necessita-se o entendimento dos valores culturais, sociais e históricos de determinado ambiente. Desse modo, cultura escolar configura-se como algo maior que o trabalho escolar realizado em cada contexto escolar, pois engloba um conjunto de fatores que consubstanciam e deliberam sobre as tramas tecidas nos espaços que perfazem esse mesmo trabalho escolar.

Com base no estado da arte realizado nas teses de doutoramento evidenciamos a presença de culturas escolares distintas, mas ainda com amarras à estrutura externa e macro do sistema educacional situação a qual nos possibilita pensar em novos estudos que atendas as demandas aqui evidenciadas. 


\section{Considerações e constatações}

$\mathrm{Na}$ intenção de realizar um tratamento dos resultados obtidos em nosso estudo do estado da arte do termo cultura escolar percebemos que, na primeira categoria Cultura e as implicações no contexto escolar, há uma forte aproximação da cultura escolar com o campo histórico e uma inter-relação deste com o espaço sócio - político e cultural das sociedades investigadas.

Na segunda categoria Cultura escolar e sua relação com o trabalho docente, podemos verificar que a cultura escolar contempla dois eixos: o primeiro deles, vinculado ao trabalho escolar tendo uma relação mais próxima com a cultura, a política e a história local sendo este, um trabalho a ser realizado por todos os agentes escolares (equipe diretiva, professores, pais, servidores, etc...); o segundo direciona-se para o trabalho docente que apresenta uma íntima relação com a organização curricular, com os conteúdos específicos de cada área a ser trabalhado sendo este, atribuído ao trabalho do professor em sala de aula.

Essa divisão conceitual nos aproxima da definição de cultura escolar posta Julia (2001) quando este autor a descreve como um conjunto de normas a ensinar e condutas a inculcar, e também do conceito de Forquin (1993) quando define a cultura escolar como uma cultura seletiva. As condutas a inculcar, como coloca Julia, são condutas amplamente difundidas nos documentos Educacionais e na teorização das Políticas Públicas, contudo, muito pouco efetivado em ações e projetos no âmbito do ensino e da aprendizagem do estudante. Compreendemos que isso pode ser visto como algo positivo posto que delibera sobre uma certa autonomia organizacional da escola e mobiliza a concretização de um espaço democrático.

No entanto, a distância entre o que está posto na cultura escolar e o que se realiza no trabalho docente não pode ser um processo de desconhecimento do que vem sendo apresentado nos diferentes espaços, mas sim, um direcionamento para a autonomia da escola. Esta constatação pode ser explicitada com os resultados da pesquisa realizada por Oliveira (2003) quando a autora procurou responder como as estratégias de resolução de problemas (fracasso escolar) da escola se materializam nas práticas escolares.

Oliveira (2003, p.153) registra, em suas considerações finais de sua pesquisa, que é “[...] possível afirmar que a escola não desenvolve, ou desenvolve de maneira muito diferente da apresentada, a maioria das ações presentes nos documentos 
consultados". Dessa forma, o que normalmente pode ser visto nas escolas é a tentativa constante de se criar a imagem de uma escola "ideal", mas o que acontece no espaço escolar geralmente costuma ser diferente.

Assim, o que se percebeu é que há uma cultura do ideal que permeia as escolas, ou seja, há um amoldamento, também denominado como uma "cultura do amoldamento" (OLIVEIRA, 2003) para responder rapidamente às demandas colocadas para a escola sem gerar discussão e preparação para os resultados que esta repercutirá. Isso implicaria diretamente no trabalho do docente posto que na escola, o professor é o sujeito que recebe as prescrições postas socialmente e tem o trabalho de operacionalizar em ações que efetivamente irão repercutir nos resultados esperados. Desse modo, é no processo que vai da tarefa prescrita, da atividade de planejamento e organização à realização da ação, que diferencia a cultura escolar ideal, do trabalho docente em sala de aula.

Com vista a recuperar o objetivo deste estudo, percebemos que a discussão da cultura em campos de conhecimento distintos e, a sua inserção nas pesquisas de doutoramento realizadas no Brasil no campo educacional, sinalizam para a complexidade que abarcam os termos: cultura escolar, $\Theta$ trabalho escolar e trabalho docente. Contudo, podemos, a partir desta análise e de nossas aproximações com o contexto escolar, colocar a cultura escolar como um conjunto de normas que, a partir da seleção de uma cultura social, define conhecimento (no âmbito curricular, a ser efetivado pelo trabalho docente) a ensinar e condutas (normas de convivência social, a ser efetivado pelo trabalho escolar) a inculcar.

Sendo assim, o levantamento e uma primeira análise dos títulos e resumos das teses nos possibilitaram uma aproximação aos estudos da cultura no campo educacional, bem como um direcionamento para futuros aprofundamentos frente a complexidade desse campo. Ainda, cabe ressaltar, que além dos autores e dos conceitos mais utilizados acerca do termo cultura escolar, pudemos verificar que dos 51 títulos das teses, 34 deles foram desenvolvidos no Estado de São Paulo, mais especificamente na Pontifícia Universidade Católica de São Paulo (PUC), na Universidade de São Paulo (USP) e na Universidade de Campinas (UNICAMP).

Além do Estado de São Paulo temos estudos referentes à cultura escolar sendo realizados no Rio de Janeiro, Minas Gerais, Rio Grande do Norte, Paraná, Mato Grosso do Sul, Rio Grande do Sul e Brasília. Estes resultados nos mostraram a concentração dos estudos sobre cultura escolar em poucos Estados e Universidades possibilitando, 
assim, um direcionamento para nossas próximas investigações a fim de aprofundar a relação que aqui se estabeleceu entre culturas escolares, trabalho escolar e trabalho docente.

\section{SCHOOL CULTURES: THE STATE OF ART IN THE CONTEXT EDUCATION}

ABSTRACT: The present study aims to establish a state of the art regarding the use of the term school culture in academic and scientific research, specifically in the doctoral theses (educational field) found in the portal of CAPES. This objective has come up with the problem of verifying the origin of the term school cultures, and how it was inserted as shown in the linked to the Educational field research. Thus, initially a survey of abstracts of doctoral theses, covering the period from 1987 to 2009, filled in the CAPES Portal was conducted. The analysis of the abstracts performed in three steps: 1 - preanalysis, 2-exploration; 3 - treatment of the results. In the categorization of the 51 theses in two parts: (1) - Culture and the implications in the school context, which is subdivided into: a) Cultural History (changes in school cultures) and; b)Culture versus School Culture and, (2) - School Culture and its relationship with academic work, which is divided into : a) School Culture (teachers and students - organization of school time and space), b)Culture versus Public Policy, c) Curriculum versus Culture and, d) Special Education versus School Culture. Realized so that the studies that discuss the school culture to indicate the complexity of school culture, school work and teaching.

KEYWORDS: School culture. School work. Teacher work.

\section{REFERÊNCIAS}

BOURDIEU, P.; PASSERON, J. C. Elementos para uma teoria do sistema de ensino. Rio de Janeiro: Francisco Alves, 1975.

CARVALHO, R. G. G. Cultura global e contextos locais: a escola como instituição possuidora de cultura própria. Revista Iberoamericana de Educación, [S.1.], v.39, n.2, jun. 2006. Disponível em: <http://www.rieoei.org/1434.htm>. Acesso em: 08 fev. 2011

CORTE, M. G. D; MOROSINI, M. C. Um olhar na produção científica sobre as práticas e estágios do curso de Pedagogia. In: IV SIMPÓSIO DE EDUCAÇÃO SUPERIOR: DESENVOLVIMENTO PROFISSIONAL DOCENTE E I FÓRUM DE PESQUISADORES EM EDUCAÇÃO SUPERIOR, 2007, Santa Maria. Anais... Santa Maria: UFSM, 2007.

FARIA FILHO, L. M. et al. A cultura escolar como categoria de análise e como campo de investigação na história da educação brasileira. Educação e Pesquisa, São Paulo, v.30, n.1, p.139-159, jan./abr. 2004.

FORQUIN, J. C. Escola e cultura: as bases sociais e epistemológicas do conhecimento 
escolar. Tradução de Guacira Lopes Louro. Porto Alegre: ARTMED, 1993.

GEERTZ, C. A Interpretação das culturas. Rio de Janeiro: LTC, 1989.

JULIA, D. A cultura escolar como objeto histórico. Revista Brasileira de História da Educação, Campinas, n.1, p.9-44, 2001.

LARAIA, R. B. Cultura um conceito antropológico. 12.ed. Rio de Janeiro: Jorge Zahar, 1999.

MINAYO, M. C. S. O desafio do conhecimento: pesquisa qualitativa em saúde. 9.ed. São Paulo: Hucitec, 2006.

NÓVOA, A. As organizações escolares em análise. Lisboa: Dom Quixote, 2005.

OLIVEIRA, T. F. M. Escola, cultura do ideal e do amoldamento. São Paulo: Iglu, 2003.

ORTIZ, R. Mundialização e cultura. São Paulo: Brasiliense, 2006.

ROMANOWSKI, J. P.; ENS, R. T. As pesquisas denominadas do tipo "estado da arte" em educação. Diálogo Educacional, Curitiba, v.6, n.19, p.37-50, set./dez. 2006.

SZYMANSKY, H. (Org.). A entrevista na pesquisa em educação: a prática reflexiva. Brasília: Líber Livro Editora, 2004.

TARDIF, M.; LESSARD, C. O trabalho docente: elementos para uma teoria da docência como profissão de interações humanas. Tradução de João Batista Kreuch. Petrópolis: Vozes, 2005.

TOYNBEE, A. J. Estudio de la historia. Rio de Janeiro: Alianza, 1971.

VIÑAO FRAGO, A. Historia de la educación e historia cultural. Revista Brasileira de Educação, São Paulo, n.0, p.63-82, set./dez.1995. 